\title{
Data report: quantitative analysis of grain size distribution for coarse sediments in an accretionary prism: an example from the Cascadia accretionary prism'
}

Yoshitaka Hashimoto $^{2}$ and Satomi Minamizawa ${ }^{2}$

\section{Chapter contents}

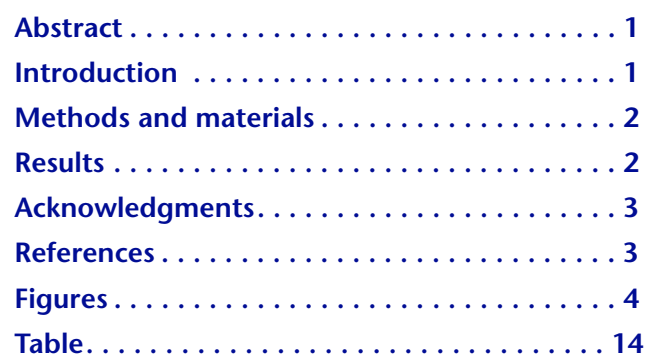

${ }^{1}$ Hashimoto, Y., and Minamizawa, S., 2009. Data report: quantitative analysis of grain size distribution for coarse sediments in an accretionary prism: an example from the Cascadia accretionary prism. In Riedel, M., Collett, T.S., Malone, M.J., and the Expedition 311 Scientists, Proc. IODP, 311: Washington, DC (Integrated Ocean Drilling Program Management International, Inc.). doi:10.2204/iodp.proc.311.205.2009 ${ }^{2}$ Department of Natural Environmental Science, Kochi University, Kochi, Japan.

Correspondence author: hassy@cc.kochi-u.ac.jp

\section{Abstract}

Grain size distributions of coarse sediments from a shallow depth of an accretionary prism were examined by two-dimensional image analysis using thin sections. The analyzed samples were obtained during Integrated Ocean Drilling Program (IODP) Expedition 311. Statistical parameters such as kurtosis, skewness, and correlation coefficients of exponential and power functions show no relationship with depth and porosity. There is an inverse relationship between the correlation coefficients of exponential and power functions, indicating that some grain size distributions can be classified. The correlations also relate to sediment textures. Samples with rounded and isolated grains have a higher correlation coefficient with the exponential function. Angular grains and a denser packing texture represent a lower correlation coefficient with the exponential function.

\section{Introduction}

Diagenetic processes are essentially dewatering processes. Porosity decreases and pore water escapes from the pore space with depth in shallower portions because of mechanical compaction. Deeper, dehydration from mineral phases will occur. Therefore, diagenetic processes are strongly related to the fluid circulation system in many sedimentary basins. Diagenetic processes are also related to changes in physical properties such as porosity, permeability, and so on. Porosity and permeability decrease because of not only mechanical compaction but also chemical precipitation as a cementation process (e.g., Houseknecht, 1987; Bjørkum et al., 1998). Changes in the physical properties control fluid pressure, which directly affects the effective stress. Therefore, rock strength and frictional strength on a fault can also be related to diagenetic processes.

A subduction zone is the largest fault fluid system on Earth. Diagenetic processes in a subduction zone are important to understanding fluid circulation around the subduction zone (e.g., Bray and Karig, 1985; Cochrane et al., 1994; Saffer et al., 2000; Saito and Goldberg, 2001), which might be related to the formation of gas hydrate and earthquakes. Diagenetic processes in a subduction zone have not been well documented thus far. These processes should differ from those in an oceanic basin because of 
tectonically driven stress or the underthrusting of sediments themselves (e.g., Moore and Karig, 1976).

Diagenetic processes include mainly of mechanical compaction, compactive cataclasis, chemical dehydration, and cementation. Those mechanisms might occur in order from shallow to deep (Hashimoto et al., 2006). The strength of compactive cataclasis for coarser sediments is well studied in laboratory experiments (e.g., Zhang et al., 1990; Wong et al., 1997). The studies provide the relationship between effective stress, porosity, and grain size at the onset of compactive cataclasis under both hydrostatic and differential stress conditions.

Grain size distribution can be used to examine whether the sediment is formed by cataclasis. For instance, in sandstone blocks from an on-land accretionary complex, grain size distribution represents a fractal distribution, which is fit by a power function within a web structure (Hashimoto et al., 2006). A web structure is known to be formed by cataclastic deformation (Byrne, 1984). On the other hand, grain size distribution in a host part of the sandstone does not show a fractal distribution but an exponential relationship (Hashimoto et al., 2006).

The fractal distribution in grain size may relate to cataclastic deformation in some cases. Because cataclasis acts to reduce grain size and porosity (Zhang et al., 1990; Wong et al., 1997), we examine parameters related to fractal distribution in grain size as a means of estimating the degree of compactive cataclasis. The sample from the on-land accretionary complex is from a portion deep enough that after the diagenetic processes were completed all of the processes were overprinted. To understand the mechanism in total, samples from shallow to deep need to be examined. In this paper, we provide grain size distributions and variations with depth and porosity for a shallow accretionary prism, the Cascadia margin.

\section{Methods and materials}

Grain size analysis was conducted by image analysis of thin sections because the distribution of unlithified sediments from ocean drilling projects can be compared with that of lithified rocks from ancient on-land accretionary complexes. Therefore, the coarser sediments were taken to be analyzed from the core to observe grains using an optical microscope. Fortunately, coarser sediments were relatively abundant in Expedition 311, although the mean grain size is mainly silt size. A total of 23 samples were collected as half-round samples from Sites U1325 to U1329. Samples were carefully moved to plastic half-round liners from archive halves and then covered by shrinkwrap to keep their shape. A subset of 15 samples was analyzed (Table T1) because it was difficult to make thin sections from unlithified sediments.

To avoid any disturbance of sample textures, halfround samples were initially impregnated with resin. The center of the sample was cut for thin sectioning (Fig. F1). An advantage of this method is that the original texture of unlithified sediments can be observed.

Image analysis was conducted using Image-J software. Maximum and minimum lengths of grains are obtained by the image analysis. Grain size is defined as a root mean of multiplication of maximum and minimum lengths of grains that are obtained from image analysis. The minimum grain size we quantitatively measured is $\sim 1 \mu \mathrm{m}$. The number of analyzed grains ranges from 200 to 1000 in each sample.

Four statistical parameters were examined to represent characteristics of grain size distributions. Two of them are kurtosis and skewness. The other two are correlation coefficients of fitting by exponential and power functions. Grains $<10 \mu \mathrm{m}$ were excluded from the correlation because the smaller grains introduce measurement error. The two correlation coefficients are named exponential-R and power-R. Figure F2 shows examples of the fitting of these functions. The examples show one of the highest values of exponential-R and power-R among the analyzed samples in this study.

\section{Results}

\section{Analysis of grain size distributions}

All results are shown in Table T1. Mean grain size is $\sim 10 \mu \mathrm{m}$ and ranges from $\sim 5$ to $\sim 20 \mu \mathrm{m}$. Figure F3 represents the relationships of mean grain size for each sample at each site with depth and porosity. There is no relationship between them.

Kurtosis is $\sim 16$ on average and ranges from $\sim 4$ to $\sim 44$ (Table T1). Skewness is $\sim 3.2$ on average and ranges from $\sim 1.8$ to $\sim 5.4$ (Table T1). Figures F4 and F5 show their relationships with depth and porosity. It is difficult to find a trend in the relationships.

Exponential-R is $\sim 0.957$ on average and ranges from 0.83 to 0.996 . Power- $\mathrm{R}$ is $\sim 0.939$ on average and ranges from 0.816 to 0.999 . Figures F6 and F7 show their relationships with depth and porosity. There are not any relationships between them. However, there is a relationship between exponential- $\mathrm{R}$ and power-R (Fig. F8). Samples with higher exponential-R values have lower power- $R$ values. The opposite is also true.

Those statistical parameters should indicate the characteristics of grain size distribution. They have, how- 
ever, no relationships with depth and porosity on the whole.

\section{Occurrences of grains in thin sections}

Samples can be classified by exponential-R or power-R because they represent the opposite values in each sample. Therefore, samples were classified into three types: high exponential-R, high power-R, and others. After reexamination of the occurrences of grains on the basis of this classification, some different characteristics in the occurrences are found with the classification.

Figure F9 shows the occurrences of grains in samples with higher exponential-R values and lower power- $\mathrm{R}$ values. Grain size is homogeneous. This homogeneous grain size can make the exponential distribution. The grains are relatively isolated with larger areas of matrix. The grains are relatively rounded. Cracks in the grains are very rare.

Figure F10 represents the occurrences of grains in samples with lower exponential-R values and higher power- $\mathrm{R}$ values. The grains show variations in their sizes. The shape of grains is relatively angular to subangular. Spaces between grains are smaller than those of the samples with higher exponential-R values, which indicates denser packing. Cracks within the grains are found in some places. Higher power-R values indicate that the grain size distribution is fractal. The distribution is the same as that within the web structure reported by Hashimoto et al. (2006).

\section{Acknowledgments}

This research used samples and/or data provided by the Integrated Ocean Drilling Program (IODP) from Expedition 311.

\section{References}

Bjørkum, P.A., Oelkers, E.H., Nadeau, P.H., Walderhaug, O., and Murphy, W.M., 1998. Porosity prediction in quartzose sandstones as a function of time, temperature, depth, stylolite frequency, and hydrocarbon saturation. AAPG Bull., 82:637-648.

Bray, C.J., and Karig, D.E., 1985. Porosity of sediments in accretionary prisms and some implications for dewater- ing processes. J. Geophys. Res., 90(B1):768-778. doi:10.1029/JB090iB01p00768

Byrne, T., 1984. Early deformation in melange terranes of the Ghost Rocks Formation, Kodiak Islands, Alaska. In Raymond, L.A. (Ed.), Melanges: Their Nature Origin, and Significance. Spec. Pap.-Geol. Soc. Am., 198:21-52.

Cochrane, G.R., Moore, J.C., MacKay, M.E., and Moore, G.F., 1994. Velocity and inferred porosity model of the Oregon accretionary prism from multichannel seismic reflection data: implications on sediment dewatering and overpressure. J. Geophys. Res., 99(B4):7033-7043. doi:10.1029/93JB03206

Hashimoto, Y., Nakaya, T., Ito, M., and Kimura, G., 2006. Tectonolithification of sandstone prior to the onset of seismogenic subduction zone: evidence from tectonic mélange of the Shimanto Belt, Japan. Geochem., Geophys., Geosys., 7(6):Q06013. doi:10.1029/ 2005GC001062

Houseknecht, D.W., 1987. Assessing the relative importance of compactional processes and cementation to the reduction of porosity in sandstones. AAPG Bull., 71:633-642.

Moore, J.C., and Karig, D.E., 1976. Sedimentology, structural geology, and tectonics of the Shikoku subduction zone, southwestern Japan. Geol. Soc. Am. Bull., 87(9):1259-1268. doi:10.1130/ 0016-7606(1976)87<1259:SSGATO>2.0.CO;2

Saffer, D.M., Silver, E.A., Fisher, A.T., Tobin, H., and Moran, K., 2000. Inferred pore pressures at the Costa Rica subduction zone: implications for dewatering processes. Earth Planet. Sci. Lett., 177(3-4):193-207. doi:10.1016/ S0012-821X(00)00048-0

Saito, S., and Goldberg, D., 2001. Compaction and dewatering processes of the oceanic sediments in the Costa Rica and Barbados subduction zones: estimates from in situ physical property measurements. Earth Planet. Sci. Lett., 191(3-4):283-293. doi:10.1016/S0012821X(01)00403-4

Wong, T.-F., David, C., and Zhu, W., 1997. The transition from brittle faulting to cataclastic flow in porous sandstones: mechanical deformation. J. Geophys. Res., 102(B2):3009-3025. doi:10.1029/96JB03281

Zhang, J., Wong, T., and Davis, D.M., 1990. Micromechanics of pressure-induced grain crushing in porous rocks. $J$. Geophys. Res., 95(B1):341-352. doi:10.1029/ JB095iB01p00341

Initial receipt: 18 June 2008

Acceptance: 18 September 2008

Publication: xx Month 2009

MS 311-205 
Figure F1. Schematic of the area of thin sections within half-round samples. Shaded area $=$ area for thin sections.

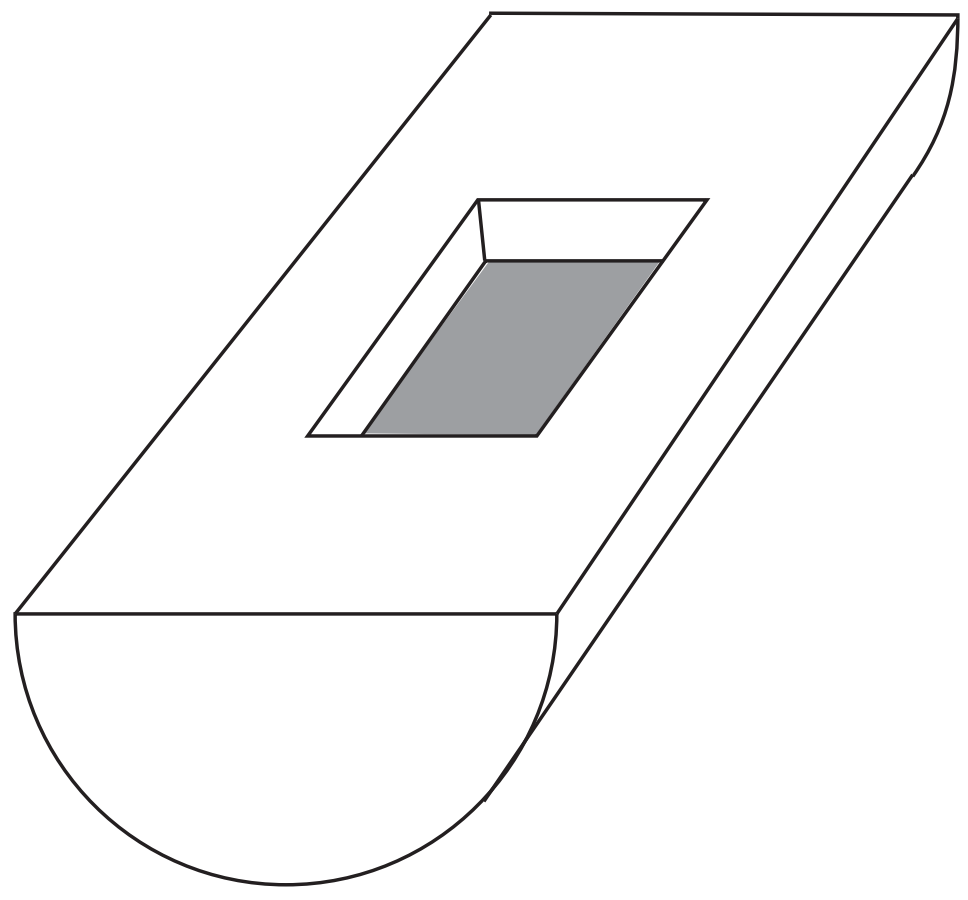


Figure F2. Examples of the fittings by (A) exponential function (Sample 311-U1329C-17H-2, 135-145 cm) and (B) power function (Sample 311-U1326C-3H-6, 75-85 cm).
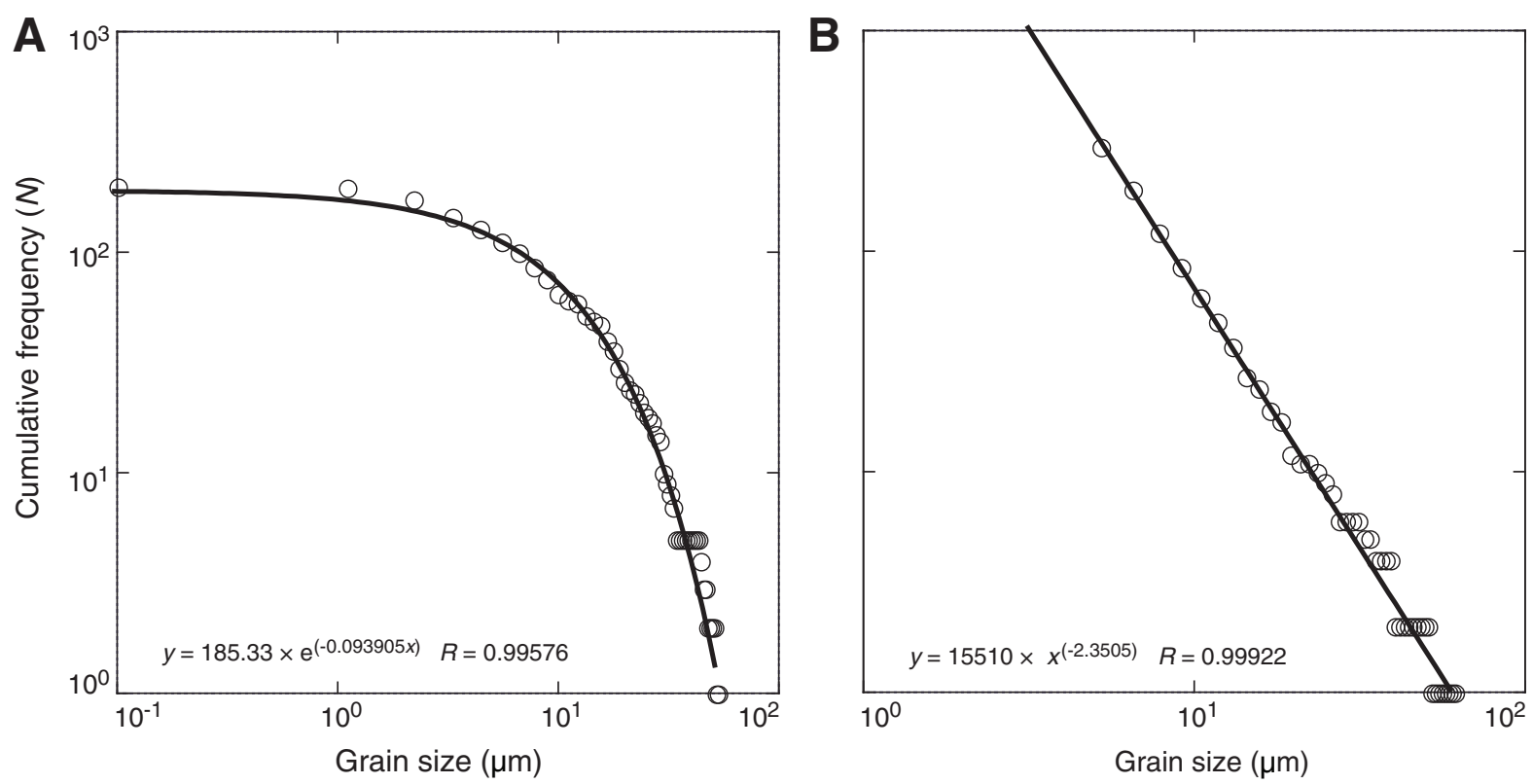
Figure F3. Relationships of grain size to (A) depth and (B) porosity at each site.
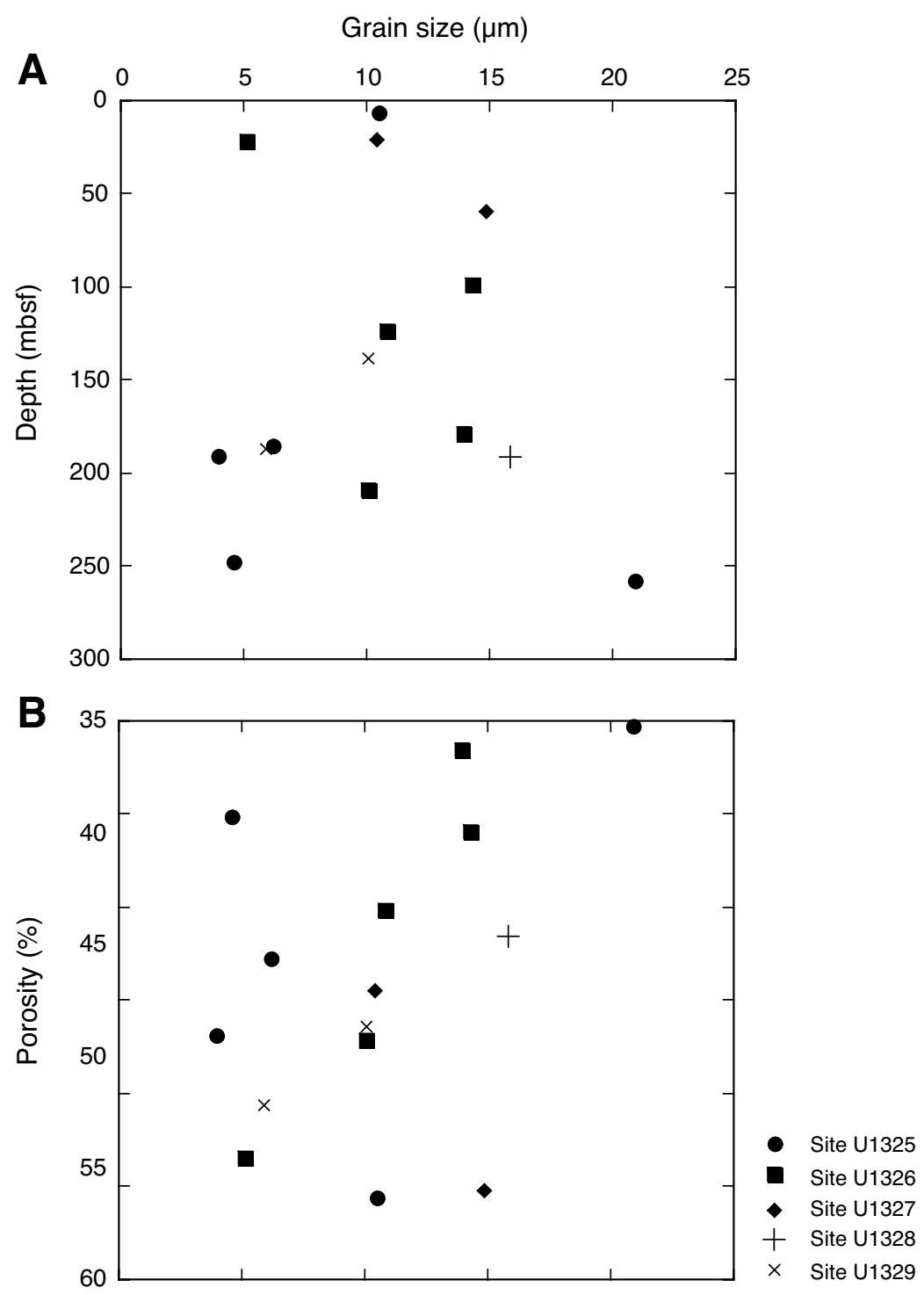
Figure F4. Relationships of kurtosis to (A) depth and (B) porosity at each site.
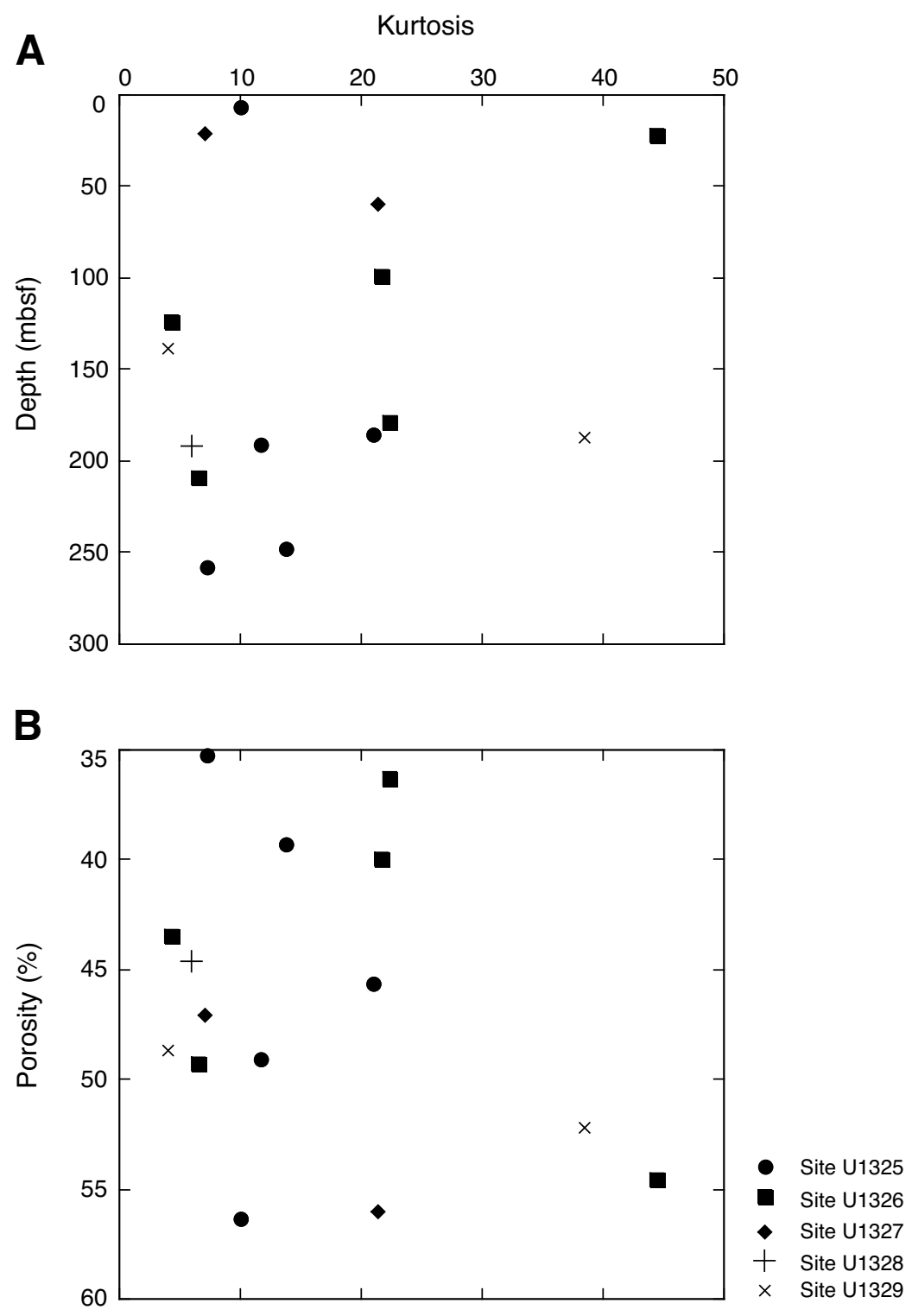
Figure F5. Relationships of skewness to (A) depth and (B) porosity at each site.
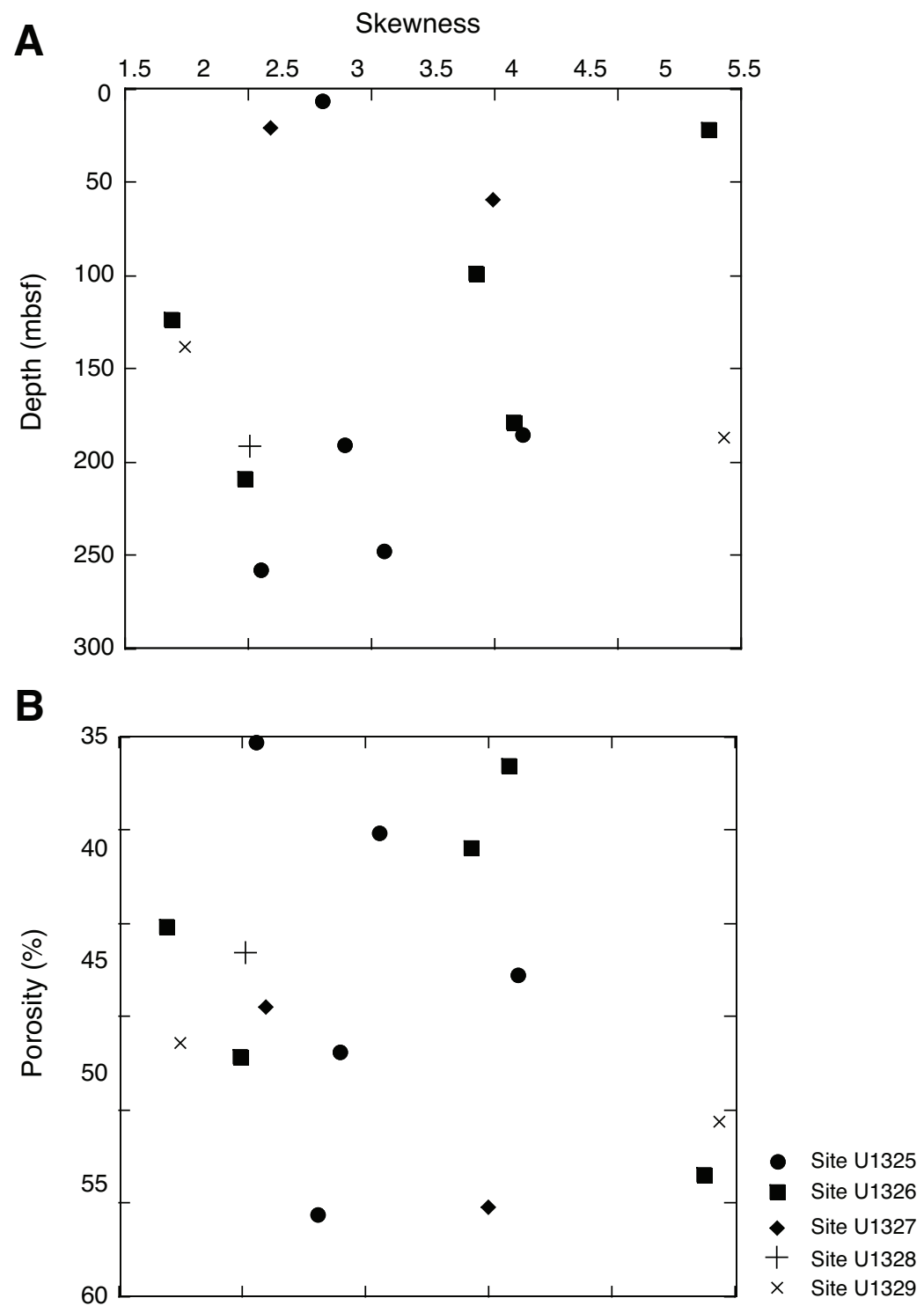
Figure F6. Relationships of exponential-R to (A) depth and (B) porosity at each site.

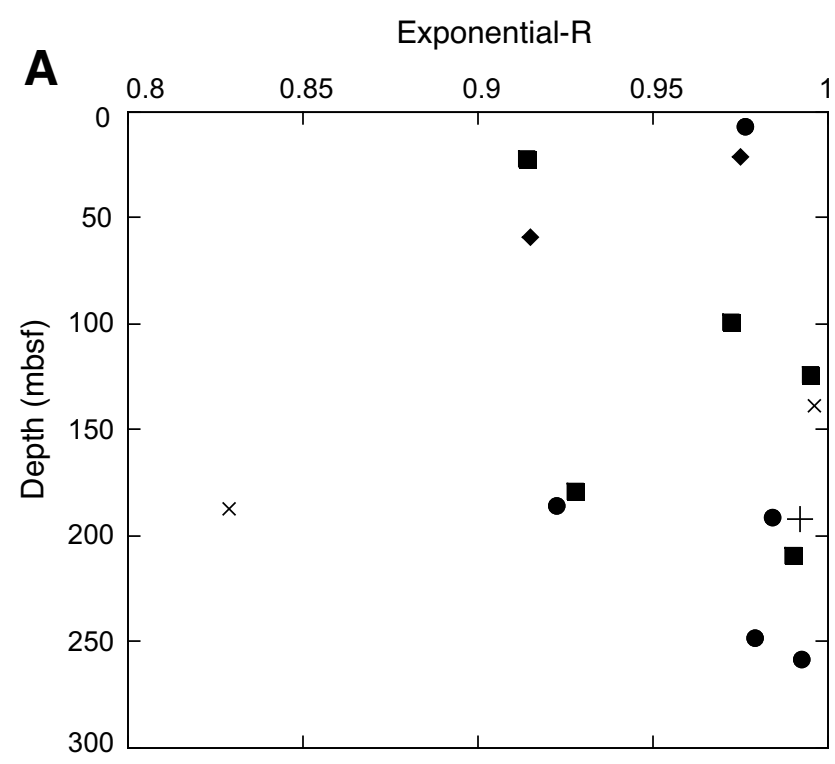

\section{B}

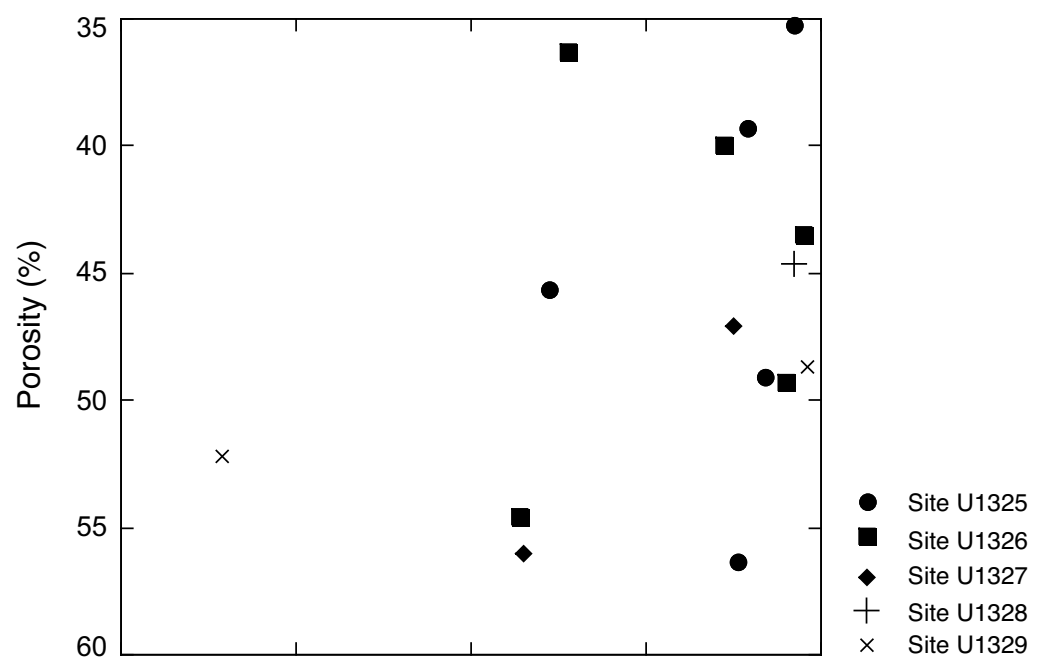


Figure F7. Relationships of power-R to (A) depth and (B) porosity at each site.

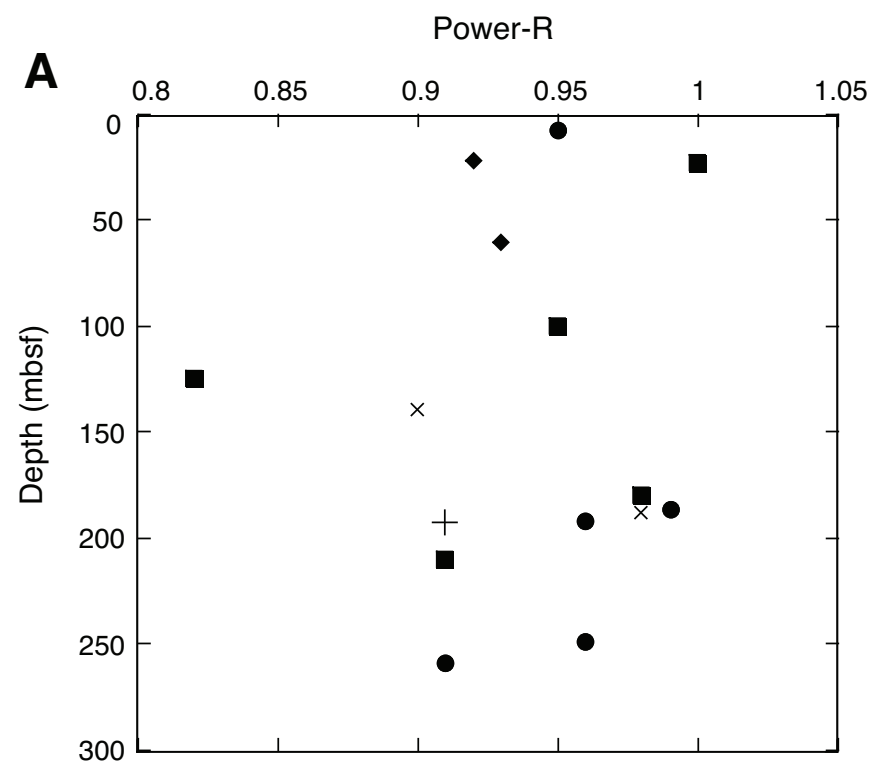

B

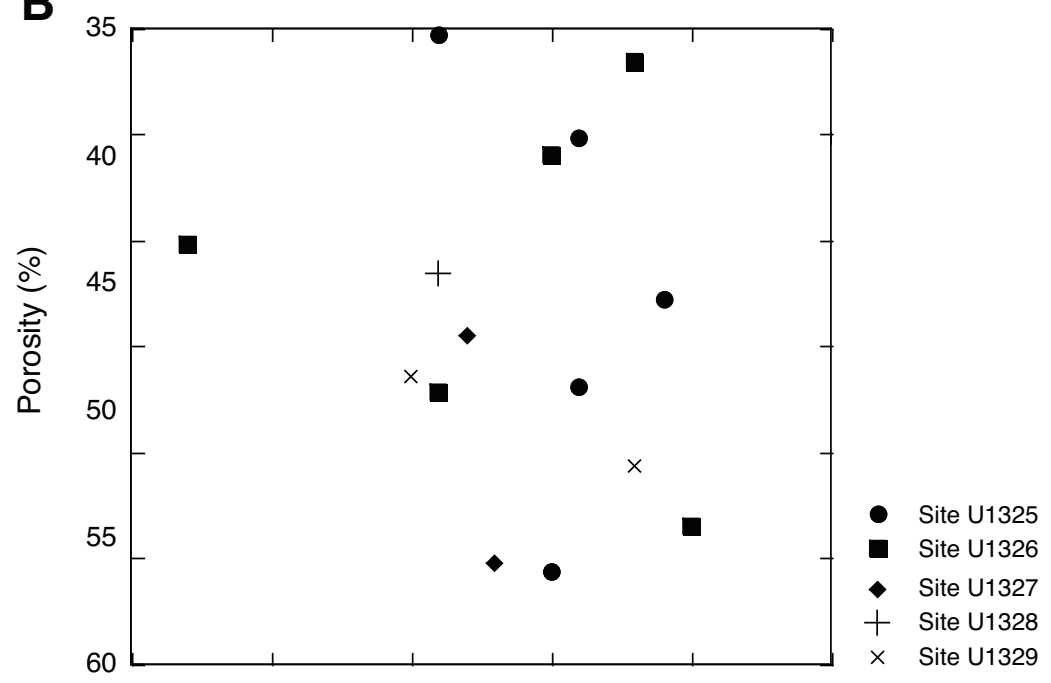


Figure F8. Relationship between exponential-R and power-R.

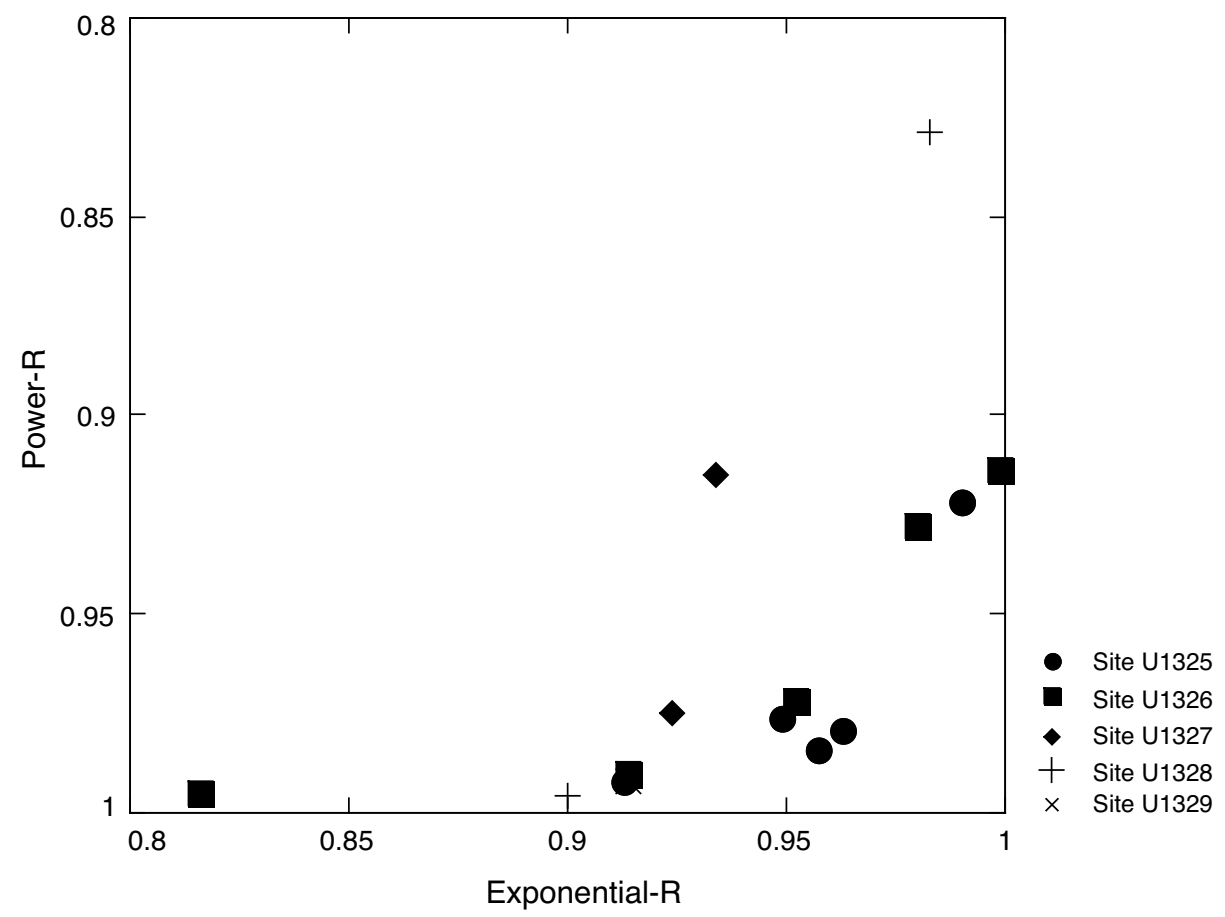


Figure F9. Photomicrographs of grains with higher exponential-R values and lower power-R values. A, B. Sample 311-U1326D-5X-6, 55-65 cm; (A) plain-polarized light; (B) cross-polarized light. C, D. Sample 311-U1329C17H-2, 135-145 cm; (C) plain-polarized light; (D) cross-polarized light. E, F. Sample 311-U1328C-16X-3, 125$150 \mathrm{~cm}$; (E) plain-polarized light; (F) cross-polarized light. G, H. Sample 311-U1325C-11X-1, 32-42 cm; (G) plain-polarized light; $(\mathrm{H})$ cross-polarized light.

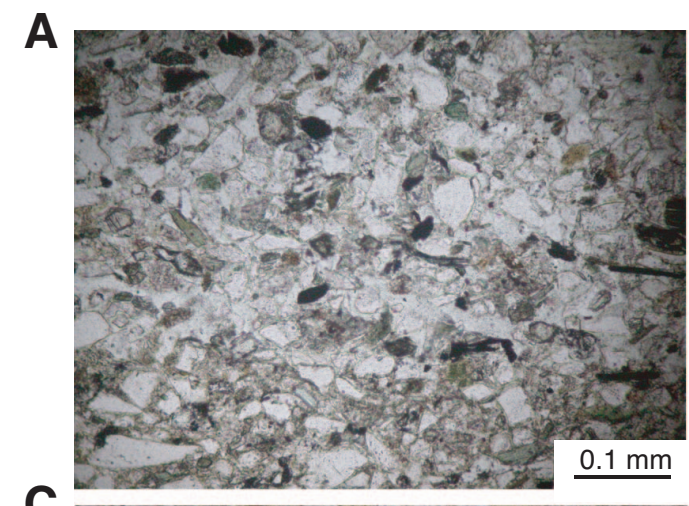

C

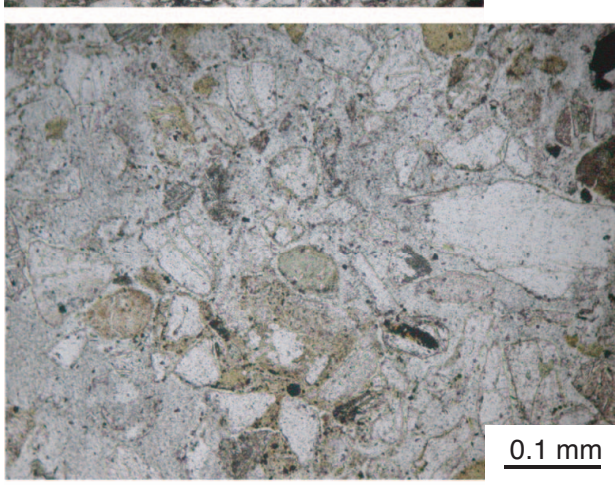

$\mathbf{E}$

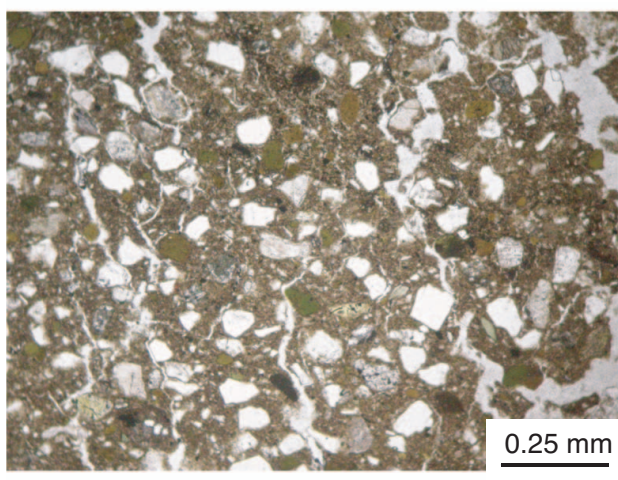

G

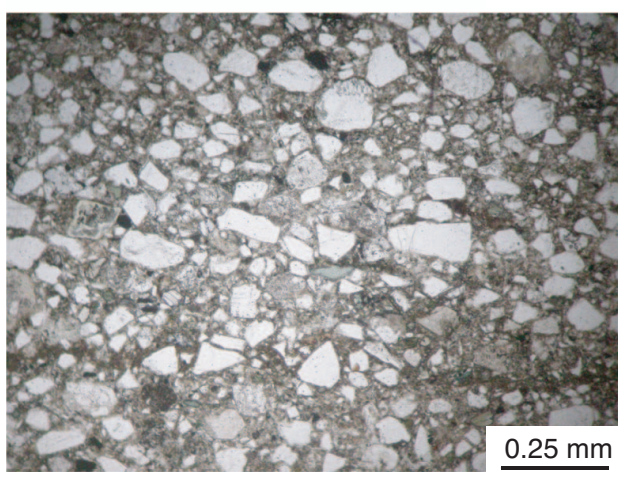

$\mathbf{B}$

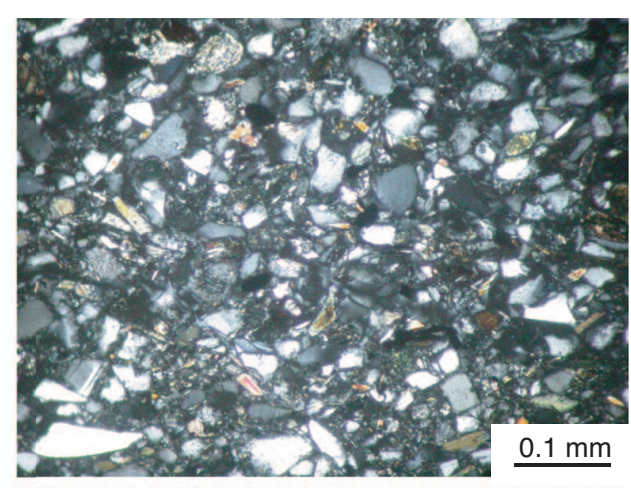

D

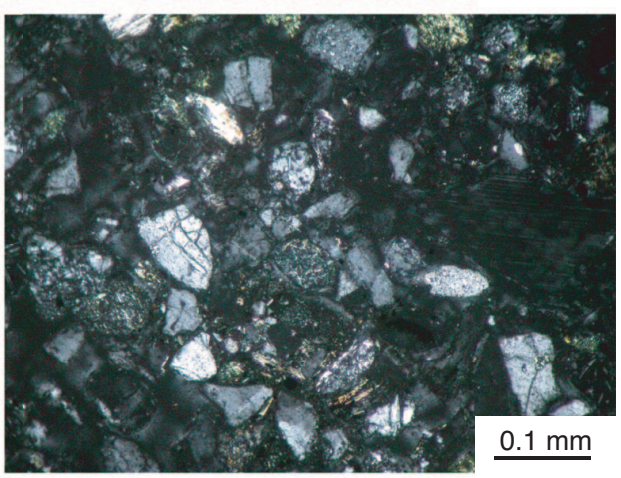

$F$

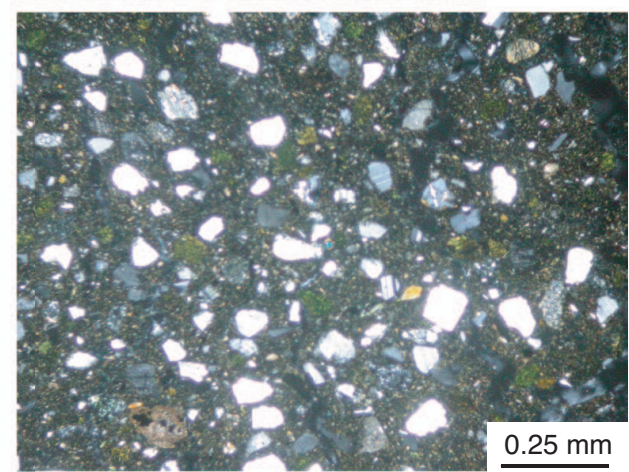

H

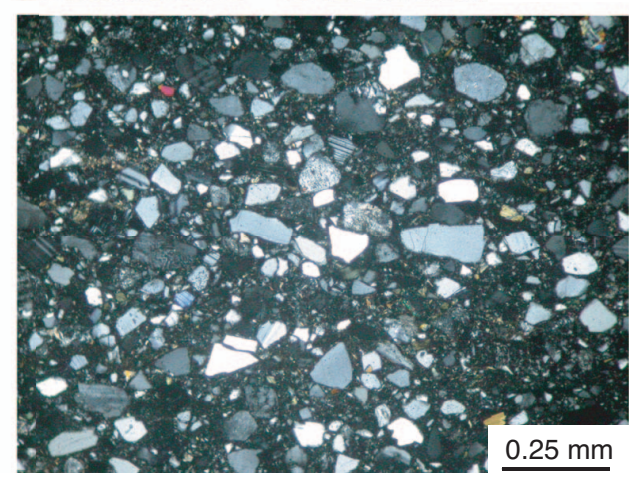


Figure F10. Photomicrographs of grains with lower exponential-R values and higher power-R values. A, B. Sample 311-U1327C-8H-3, 82-92 cm; (A) plain-polarized light; (B) cross-polarized light. C, D. Sample 311-U1329C22X-CC, 58-68 cm; (C) plain-polarized light; (D) cross-polarized light. E, F. Sample 311-U1326C-3H-6, 75-85 cm; (E) plain-polarized light; (F) cross-polarized light. G, H. Sample 311-U1325B-24X-5, 98-108 cm; (G) plainpolarized light; (H) cross-polarized light. I, J. Sample 311-U1326D-11X-4, 30-40 cm; (I) plain-polarized light; (J) cross-polarized light.
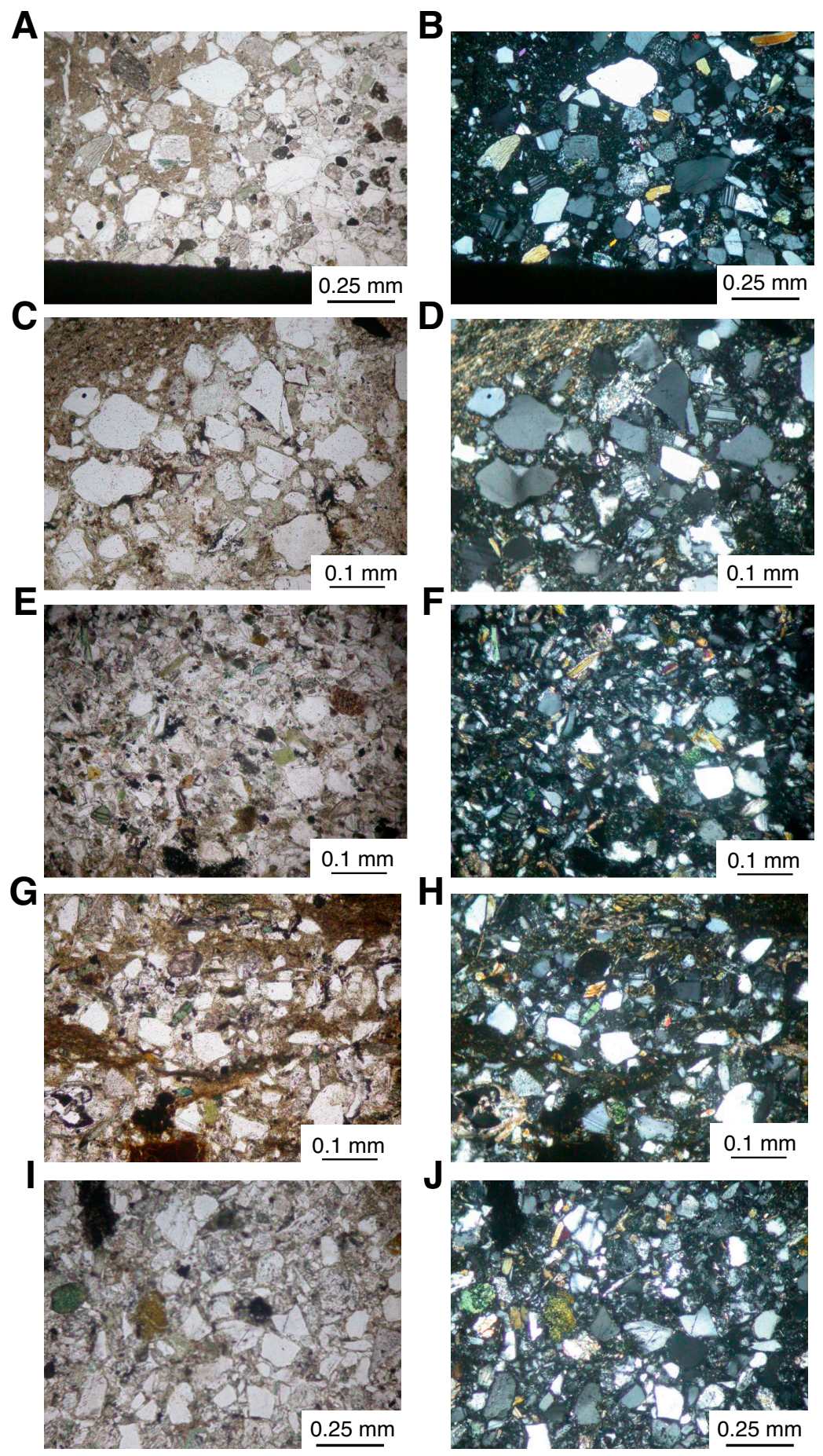
Table T1. Results of grain size analysis. (See table notes.)

\begin{tabular}{|c|c|c|c|c|c|c|c|c|}
\hline $\begin{array}{l}\text { Core, section, } \\
\text { interval }(\mathrm{cm})\end{array}$ & $\begin{array}{l}\text { Depth } \\
\text { (mbsf) }\end{array}$ & $\begin{array}{l}\text { Porosity } \\
\text { (\%) }\end{array}$ & $\begin{array}{c}\text { Exponential- } \\
\mathrm{R}\end{array}$ & $\begin{array}{c}\text { Power- } \\
\text { R }\end{array}$ & Kurtosis & Skewness & $\begin{array}{c}\text { Grain } \\
\text { size }(\mu \mathrm{m})\end{array}$ & $\begin{array}{l}\text { Grains } \\
(N)\end{array}$ \\
\hline \multicolumn{9}{|l|}{ 311-1325B- } \\
\hline $1 \mathrm{H}-5,26-37$ & 6.260 & 56.3 & 0.976 & 0.949 & 9.952 & 2.775 & 10.520 & 268 \\
\hline $24 X-5,98-108$ & 185.250 & 45.6 & 0.922 & 0.990 & 20.953 & 4.079 & 6.203 & 485 \\
\hline \multicolumn{9}{|l|}{ 311-1325C- } \\
\hline $1 X-2,59-68$ & 190.890 & 49.1 & 0.984 & 0.957 & 11.684 & 2.925 & 3.942 & 364 \\
\hline $9 X-1,96-106$ & 247.460 & 39.3 & 0.979 & 0.963 & 13.755 & 3.175 & 4.620 & 360 \\
\hline $11 X-1,32-42$ & 257.420 & 35.2 & 0.992 & 0.913 & 7.261 & 2.380 & 20.938 & 763 \\
\hline \multicolumn{9}{|l|}{ 311-1326C- } \\
\hline $3 \mathrm{H}-6,75-85$ & 21.650 & 54.6 & 0.914 & 0.999 & 44.444 & 5.291 & 5.137 & 908 \\
\hline \multicolumn{9}{|l|}{ 311-1326D- } \\
\hline $3 X-1,88-97$ & 98.980 & 40.0 & 0.972 & 0.952 & 21.733 & 3.774 & 14.294 & 447 \\
\hline $5 X-6,55-65$ & 124.150 & 43.5 & 0.995 & 0.816 & 4.243 & 1.799 & 10.867 & 358 \\
\hline $11 X-4,30-40$ & 178.990 & 36.3 & 0.928 & 0.980 & 22.401 & 4.026 & 13.949 & 991 \\
\hline $14 X-6,1-11$ & 209.510 & 49.3 & 0.990 & 0.914 & 6.520 & 2.273 & 10.056 & 380 \\
\hline \multicolumn{9}{|l|}{$311-1327 C-$} \\
\hline $3 \mathrm{H}-4,69-80$ & 20.790 & 47.1 & 0.975 & 0.924 & 7.075 & 2.449 & 10.386 & 298 \\
\hline $8 \mathrm{H}-3,82-92$ & 59.420 & 56.0 & 0.915 & 0.934 & 21.336 & 3.889 & 14.845 & 922 \\
\hline \multicolumn{9}{|l|}{$311-1328 C-$} \\
\hline $16 X-3,125-150$ & 191.750 & 44.6 & 0.992 & 0.914 & 5.945 & 2.317 & 15.855 & 576 \\
\hline \multicolumn{9}{|l|}{$311-1329 C-$} \\
\hline $17 \mathrm{H}-2,135-145$ & 138.450 & 48.7 & 0.996 & 0.900 & 4.007 & 1.892 & 10.094 & 199 \\
\hline $22 X-C C, 58-68$ & 187.610 & 52.2 & 0.829 & 0.983 & 38.518 & 5.386 & 5.875 & 790 \\
\hline Averages: & 141.239 & 46.5 & 0.957 & 0.939 & 15.988 & 3.229 & 10.505 & 541 \\
\hline
\end{tabular}

Notes: $\mathrm{mbsf}=$ meters below seafloor. $N=$ number . 